\title{
OPEN HAEMORRHOIDECTOMY VERSUS STAPLED HAEMORRHOIDOPEXY- A PROSPECTIVE STUDY IN A TERTIARY HOSPITAL IN SOUTH INDIA
}

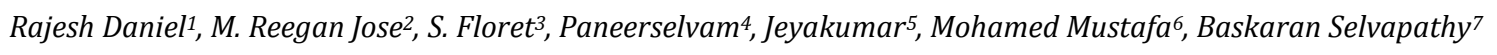

${ }^{1}$ Assistant Professor, Department of General Surgery, SRM Medical College Hospital and Research Centre, Kattankulathur,

Kancheepuram, Tamilnadu.

${ }_{2}^{2}$ Postgraduate Student, Department of Surgery, SRM Medical College Hospital and Research Centre, Kattankulathur, Kancheepuram,

Tamilnadu.

${ }^{3}$ Retired Professor, Department of Surgery, SRM Medical College Hospital and Research Centre, Kattankulathur, Kancheepuram,

Tamilnadu.

${ }^{4}$ Retired Professor, Department of Surgery, SRM Medical College Hospital and Research Centre, Kattankulathur, Kancheepuram,

Tamilnadu.

5Professor and HOD, Department of Surgery, SRM Medical College Hospital and Research Centre, Kattankulathur, Kancheepuram,

Tamilnadu.

${ }^{6}$ Professor, Department of General Surgery, SRM Medical College Hospital and Research Centre, Kattankulathur, Kancheepuram,

Tamilnadu.

${ }^{7}$ Retired Professor, Department of General Surgery, SRM Medical College Hospital and Research Centre, Kattankulathur,

Kancheepuram, Tamilnadu.

\begin{abstract}
BACKGROUND
Haemorrhoids are one of the most common benign anorectal problems worldwide. The treatment of third- and fourth-degree haemorrhoids is surgical. Surgical haemorrhoidectomy and Stapled haemorrhoidopexy are the currently available surgical interventions in the management of haemorrhoids.

The present study is designed to compare the short-term outcomes of Stapled haemorrhoidopexy with Milligan-Morgan (Open) Haemorrhoidectomy.
\end{abstract}

\section{MATERIALS AND METHODS}

This was a prospective and comparative study done among 90 patients admitted in surgical ward of SRM Medical College, Hospital and Research Centre, Kattankulathur between 2014 and 2015. Forty five patients underwent Open Haemorrhoidectomy (OH) and 45 patients underwent Stapled Haemorrhoidopexy (SH). The duration of surgery, postoperative pain and immediate postoperative complications between $\mathrm{OH}$ (Open Haemorrhoidectomy) and SH (Stapled Haemorrhoidectomy) were compared. Statistical significance was tested by Chi-square test, student's ' $t$ ' test, Mann-Whitney ' $U$ ' test and Fisher Exact Test.

\section{RESULTS}

In this study, among 90 study participants 57 were males and 33 were females. The mean duration of surgery was 35 minutes ranging from 25 to 55 minutes in Stapled Haemorrhoidopexy (SH) and the mean duration of surgery was 46 minutes ranging from 25 to 55 minutes in Open Haemorrhoidectomy $(\mathrm{OH})$. Duration of surgery is significantly low in stapled group (p $<0.001)$. The pain was assessed using a Visual Analog Scale (VAS). The pain score was below 3 in patients who underwent Stapled Haemorrhoidopexy (SH) and significantly higher in patients who underwent Open Haemorrhoidectomy at 6 hrs. (p < 0.001$), 12$ hrs. $(\mathrm{p}<0.05)$ and $24 \mathrm{hrs} .(\mathrm{p}<0.01)$. The immediate post-operative pain is significantly less in Stapled Haemorrhoidopexy (SH) group (28.9\%) than the Open Haemorrhoidectomy $(57.8 \%)(\mathrm{p}<0.01)$.

\section{CONCLUSION}

The findings of our study confirm that patient who underwent Stapled Haemorrhoidopexy (SH) is associated with shorter duration of surgery, less postoperative pain and minimal immediate post-operative complication. We conclude that Stapled Haemorrhoidopexy (SH) is safe with many short-term benefits.

\section{KEYWORDS}

Stapled Haemorrhoidopexy, Open Haemorrhoidectomy, Post-Operative Complications, Postoperative Pain.

HOW TO CITE THIS ARTICLE: Daniel R, Jose MR, Floret S, et al. Open haemorrhoidectomy versus stapled haemorrhoidopexy- a prospective study in a tertiary hospital in South India. J. Evolution Med. Dent. Sci. 2017;6(52):3939-3942, DOI: $10.14260 /$ Jemds/2017/852

Financial or Other, Competing Interest: None.

Submission 23-05-2017, Peer Review 22-06-2017,

Acceptance 17-06-2017, Published 29-06-2017.

Corresponding Author:

Dr. Rajesh Daniel,

\#6, Church Lane,

(3rd lane), Ritherdon Road,

Vepery, Chennai-600007, Tamilnadu.

E-mail: rajeshdaniel1112@gmail.com

DOI: $10.14260 /$ jemds $/ 2017 / 852$

\section{(c) (i) $\ominus$}

\section{BACKGROUND}

Haemorrhoids are one of the most common benign anorectal problems worldwide. The treatment of third- and fourthdegree haemorrhoids is surgical. ${ }^{1}$ Haemorrhoidectomy is one of the most commonly performed anorectal operations. ${ }^{2}$

Milligan-Morgan Haemorrhoidectomy as described in 1937 has remained the most popular among many surgical techniques proposed. ${ }^{3}$

Surgical haemorrhoidectomy is a painful procedure for a fairly benign disease, causing postoperative pain needing 
about 2 - 3 days of hospital stay with a convalescence of at least one month., 4 Patients will frequently avoid definitive treatment of their disease for many years, so as to avoid this very problem. Also, the high postoperative morbidity and long recovery has prompted the need for an alternative procedure. Several techniques including diathermy haemorrhoidectomy, dilatation with banding and cryo haemorrhoidectomy have been tried. Haemorrhoidopexy offers a significantly less painful alternative that provides patients definitive treatment of their disease in a single setting. Stapled haemorrhoidopexy, first described in 1995 is an exciting modality that represents a paradigm change in the management of haemorrhoids. ${ }^{6}$ It has been associated with improved short-term outcomes including less postoperative pain, shorter operating times, earlier return to work and greater patient satisfaction. ${ }^{4,5,7,8,9}$ Right from the earliest study, there is a high patient satisfaction rate. However, most of these studies were conducted in highly specialised centres. The present study is designed to compare the short-term results of Stapled haemorrhoidopexy (SH) with Open Haemorrhoidectomy $(\mathrm{OH})$ with respect to Operating time, Post-operative pain and Immediate Post-operative complications. Our goals were to find out if the results of the Stapled Haemorrhoidopexy are the same as those reported in the literature when the operation is performed at independent centres.

\section{MATERIALS AND METHODS}

This study was done as a non-randomised interventional study among ninety patients undergoing surgery for haemorrhoids at SRM Medical College, Kattankulathur between June 2014 and August 2015. All the patients presenting with Grade 3 and Grade 4 Haemorrhoids and between the age of 18 to 60 years were included in the study. The Exclusion Criteria included acute haemorrhoidal episodes with thrombosis prior to haemorrhoidectomy, intercurrent anal pathology (eg. Fistula-in-ano and anal fissure), prolapse of single anal cushion and anal stenosis.

Forty five patients underwent Milligan-Morgan technique of Open Haemorrhoidectomy and forty five patients underwent Longo technique of Stapled Haemorrhoidopexy. Patients were allocated into either of the groups on alternate basis. The study was approved by the Institutional Ethics Committee and written informed consent was taken from the patients participating in the study. Patients were subjected to clinical examination and routine laboratory investigations preoperatively. All patients were operated on an in-patient basis. Patient's hospital stay for analysis was calculated starting from the day of surgery. Preoperatively, patients were kept nil per oral overnight and received a phosphate enema in the morning of day of surgery. One dose of ciprofloxacin and metronidazole were given at the time of anaesthesia for surgery. All operations were performed in the lithotomy position under spinal anaesthesia. Patients were re-examined under anaesthesia to confirm the grade of haemorrhoids and to rule out associated anal pathologies like anal fissure and fistula in anus.

In this study, Milligan-Morgan technique of Open Haemorrhoidectomy was followed. The stapled procedure was performed according to the technique described by Longo. A 33-mm circular stapling device part of PPH03 kit (Proximate; Ethicon Endo-Surgery, Cincinnati, Ohio, USA) was used. The PPH03 kit includes all of the required components of the procedure except for a suture. The kit contains a stapling device, circular anoscope (with an obturator), a suturing anoscope which facilitates the placement of the purse string and a suture threader which is a hook-shaped instrument used to pull the tail of the purse string through the head of the stapling instrument.

A small dressing is applied following wound cleansing. Post-operative management consisted of standard nursing care and analgesia. Post-operative pain was managed according to the guidelines of French Anaesthesia Society. Pain was assessed using a Visual Analog Scale (VAS) Score, where 0 represented no pain and 10 represented the worst pain ever.

The pain score was recorded every 6 hours, 12 hours and 24 hours after surgery. The aim was to keep the Visual Analog Scale (VAS) score below 3 with adequate analgesia. Prescribed analgesics were classified using the World Health Organization (WHO). Analgesics were administered on the basis of the pain intensity scale score in $<3$, class I analgesic (Paracetamol) between 3 and 5, class II analgesic (Codeine, dextropropoxyphene-paracetamol) or $>5$, class III analgesic (with paracetamol). If a given analgesic was having a partial effect, an analgesic of the next class was prescribed.

In addition to analgesics, patients are advised Antibiotics (in tablet form) Ciprofloxacin $500 \mathrm{mg}$ twice daily, Metronidazole $400 \mathrm{mg}$ thrice daily and Syrup Lactulose 20 $\mathrm{mL}$ at bedtime for two weeks. Patients undergoing Open Haemorrhoidectomy are also advised Sitz bath twice daily for two weeks. Patients were discharged when pain control and home circumstances permitted. Patients were reviewed at 1 week and 3 weeks postoperatively and between 6 - 10 weeks postoperatively. On followup patients were asked to rate the control of their symptoms, degree of continence to flatus and faeces, duration of return to normal activities and any other problems they had. A physical examination was also carried out at each followup. The outcome measures were postoperative pain, analgesia requirement, operative time, hospital stay, time to return to normal activity, continence, patient satisfaction and complications. MIPH Patient Data Collection Sheet was used for data collection.

\section{Statistical Methods}

Descriptive statistical analysis has been carried out in the present study. Significance is assessed at 5\% level of significance, student's ' $\mathrm{t}$ ' test (two-tailed, independent) has been used to find the significance of study parameters on continuous scale in parametric condition between two groups Intergroup analysis) and Mann-Whitney U test (two-tailed, dependent) has been used to find the significance of study parameters on continuous scale in non-parametric condition within each group. Chi-square/Fisher Exact test has been used to find the significance of study parameters on categorical scale between two groups.

\section{RESULTS}

The results of ninety patients who underwent surgery for haemorrhoids are presented here. Among the ninety patients, forty five patients underwent Milligan-Morgan technique of Open Haemorrhoidectomy and forty five patients underwent Longo technique of Stapled Haemorrhoidopexy. Age characteristics of both the groups are presented in Table 1. There is no significant difference in age distribution in the two groups, but sex-wise significantly greater proportion of males underwent Open Haemorrhoidectomy (73.3\%) than 
Stapled Haemorrhoidopexy (53.3\%) $(\mathrm{p}<0.05)$.

\begin{tabular}{|c|c|c|c|c|c|c|}
\hline \multirow{2}{*}{$\begin{array}{c}\text { Age in } \\
\text { Years }\end{array}$} & Stapled & \multicolumn{2}{c|}{ Open } & \multicolumn{2}{c|}{ Total } \\
\cline { 2 - 7 } & No. & $\mathbf{\%}$ & No. & $\%$ & No. & $\%$ \\
\hline $21-30$ & 11 & 24.4 & 14 & 31.1 & 25 & 27.8 \\
\hline $31-40$ & 14 & 31.1 & 11 & 24.4 & 25 & 27.8 \\
\hline $41-50$ & 15 & 33.3 & 13 & 28.9 & 28 & 31.0 \\
\hline $51-60$ & 5 & 11.1 & 5 & 11.1 & 10 & 11.1 \\
\hline$>60$ & 0 & 0.0 & 2 & 4.4 & 2 & 2.1 \\
\hline Total & $\mathbf{4 5}$ & $\mathbf{1 0 0 . 0}$ & $\mathbf{4 5}$ & $\mathbf{1 0 0 . 0}$ & $\mathbf{9 0}$ & $\mathbf{1 0 0 . 0}$ \\
\hline Mean \pm SD & $39.69 \pm 9.49$ & $39.02 \pm 11.03$ & $39.36 \pm 10.22$ \\
\hline Table 1. Comparison of Age Distribution of Patients \\
Studied \\
\hline
\end{tabular}

Samples are age matched with $\mathrm{p}=0.759$

\begin{tabular}{|c|c|c|c|c|c|c|}
\hline & & Stapled & & Open & & Total \\
\hline Grades & No. & $\mathbf{\%}$ & No. & $\%$ & No. & \% \\
\hline Grade 3 & 22 & 48.9 & 21 & 46.7 & 43 & 47.8 \\
\hline Grade 4 & 23 & 51.1 & 24 & 53.3 & 47 & 52.2 \\
\hline Total & $\mathbf{4 5}$ & $\mathbf{1 0 0 . 0}$ & $\mathbf{4 5}$ & $\mathbf{1 0 0 . 0}$ & $\mathbf{9 0}$ & $\mathbf{1 0 0 . 0}$ \\
\hline Table 2. Comparison of Grade of Patients Studied \\
\hline
\end{tabular}

The proportion of patients included with Grade 3 and Grade 4 haemorrhoids were similar in Open Haemorrhoidectomy and Stapled Haemorrhoidopexy group (Table 2). The mean duration of surgery is greater in Open Haemorrhoidectomy (mean $=45$ mins) than Stapled Haemorrhoidopexy (mean $=35$ mins) (Table 3). The mean pain intensity scores were significantly greater in Open Haemorrhoidectomy than Stapled Haemorrhoidopexy at 6, 12 and 24 hours post-surgery (Table 4). Greater proportion of patients who underwent Open Haemorrhoidectomy (57.8\%) than patients who underwent Stapled Haemorrhoidopexy $(28.9 \%)(\mathrm{p}<0.01)$.

\begin{tabular}{|c|c|c|c|c|}
\hline Duration of & \multicolumn{2}{|c|}{ Stapled } & \multicolumn{2}{c|}{ Open } \\
\cline { 2 - 5 } Surgeries (Minutes) & No. & \% & No. & \% \\
\hline $20-30$ & 17 & 37.8 & 4 & 8.9 \\
\hline $31-40$ & 22 & 48.9 & 13 & 28.9 \\
\hline $41-50$ & 5 & 11.1 & 16 & 35.6 \\
\hline$>50$ & 1 & 2.2 & 12 & 26.7 \\
\hline Total & $\mathbf{4 5}$ & $\mathbf{1 0 0 . 0}$ & $\mathbf{4 5}$ & $\mathbf{1 0 0 . 0}$ \\
\hline Mean + SD & \multicolumn{3}{|c|}{$35.22 \pm 7.23$} & $\mathbf{4 5 . 6 7 \pm 1 1 . 9 4}$ \\
\hline Table 3. Comparison of Duration of Surgeries \\
\hline
\end{tabular}

\begin{tabular}{|c|c|c|c|}
\hline $\begin{array}{c}\text { Pain Scores (Pain } \\
\text { Intensity Scale) }\end{array}$ & Stapled & Open & P value \\
\hline 6 hours & $1.78 \pm 0.77$ & $2.89 \pm 0.86$ & $<0.001^{* *}$ \\
\hline 12 hours & $1.82 \pm 0.61$ & $2.13 \pm 0.82$ & $0.047^{*}$ \\
\hline 24 hours & $1.42 \pm 0.62$ & $1.89 \pm 0.80$ & $0.003^{* *}$ \\
\hline Table 4. Comparison of Pain Scores in Two Groups of \\
Patients \\
\hline
\end{tabular}

$P$ values are obtained based on Mann-Whitney U test.

\begin{tabular}{|c|c|c|c|c|c|}
\hline \multirow{2}{*}{ Complications } & \multicolumn{2}{|c|}{ Stapled (n=45) } & \multicolumn{2}{c|}{ Open (n=45) } & \multirow{2}{*}{ P value } \\
\cline { 2 - 5 } & No. & $\mathbf{\%}$ & No. & \% & \\
\hline Retention & 7 & 15.6 & 14 & 31.1 & 0.081 \\
\hline Bleeding & 5 & 11.1 & 9 & 20.0 & 0.245 \\
\hline Pain & 13 & 28.9 & 26 & 57.8 & 0.006 \\
\hline Incontinence & 0 & 0.0 & 2 & 4.4 & 0.494 \\
\hline
\end{tabular}

Table 5. Immediate Post-Operative Complications

\section{DISCUSSION}

Ninety patients undergoing surgery for Haemorrhoids at SRM Medical College, Kattankulathur fulfilled the criteria and were included in our study. Forty five underwent Longo technique of Stapled Haemorrhoidopexy and forty five underwent Milligan-Morgan technique of Open Haemorrhoidectomy. The Duration of Surgery (minutes) was compared in the two groups. In the Stapled group, 37.8\% underwent within 20 30 mins. The mean duration of surgery was 35 mins, ranging from 25 to 55 minutes. In the Open group mean of 46 minutes, ranging from 25 to 55 minutes. Duration of surgery is significantly low in stapled group with $(\mathrm{p}<0.001)$. This is similar to the observation of other studies. However, the duration is 5 to 10 minutes, longer than observed by many others (Rowsell et al, 2000; Mehigan BJ, 2000; Khalil KH, 2000; Bikhchandani J, 2005).10,11,12

Tjandra JJ and Chan MK (2007) published systematic review on Stapled Haemorrhoidopexy of all randomised, controlled trials until August 2006.13 Stapled Haemorrhoidopexy was associated with less operating time (Weighted mean difference, -11.35 minutes; $p=0.006$ ). In our study, the mean difference was comparable (11 mins). Stolfi et al (2008) in a study involving one hundred and seventy one patients comparing Stapled Haemorrhoidopexy and Milligan-Morgan technique, mean surgical time was 28 mins. ${ }^{14}$ The largest trial describing experience with 3,711 Stapled haemorrhoidopexies was published recently by $\mathrm{Ng}$ $\mathrm{KH}$, et al (2006). ${ }^{15}$ The median duration of operation was 15 mins (Range 5 to 45 mins), much lower than most studies.

In our study, post-operative pain was managed according to the guidelines of French Anesthesia Society. Pain was assessed using a Visual Analog Scale (VAS). Pain scores were significantly higher in the open group at 6 hours, 12 hours, 24 hours and at first defecation. Tjandra JJ et al (2007) report less pain after Stapled haemorrhoidopexy, as evidenced by lower pain scores at rest and on defecation and 37.6 percent reduction in analgesic requirement.

Post-surgery, six patients had bleeding as compared to 10 in the open group $(13 \%, 22 \%)$. Urinary retention was also found to be higher in the open group. None in the stapled group had a residual prolapse. There was no incontinence in any group at 6 months. At 1 month, three patients in the open group reported incontinence to flatus and faeces. No report of incontinence in stapled group.

Jayaraman S et al, Cochrane Database Syst Rev. in $2006^{16}$ on Stapled versus conventional surgery for haemorrhoids noted that though associated with comparable short-term results, Stapled haemorrhoidopexy is associated with a higher long-term risk of haemorrhoid recurrence and the symptom of prolapse. The authors concluded that conventional excisional surgery remains the "gold standard" in the surgical treatment of internal haemorrhoids, if haemorrhoid recurrence and prolapse are the most important clinical outcomes. However, Tjandra JJ and Chan MK (2007) systematic review stated that although there was increase in the recurrence of haemorrhoids at one year or more after stapled procedure the overall need of surgical and nonsurgical re-intervention after the two procedures was similar. The conclusion of Stapled Haemorrhoidopexy is safe with many short-term benefits and the long-term results are similar to conventional procedure.

The limitation of the study was only 90 subjects taken in this study. If the number of subjects is more, the outcome of the results could have been much more significant. This study is of short duration, long-term outcome is better assessed 
with prolonged followup for complications.

\section{CONCLUSION}

After comparison between Open Haemorrhoidectomy with Stapled Haemorrhoidopexy, our study confirms that Stapled Haemorrhoidopexy is associated with shorter duration of surgery, less postoperative pain with minimal post-operative complications as compared with Milligan-Morgan (Open) Haemorrhoidectomy. We conclude that Stapled Haemorrhoidopexy is safe with many short-term benefits. It is a novel technique and has emerged as an alternative to Open Haemorrhoidectomy.

\section{REFERENCES}

[1] Sayfan J, Becker A, Koltun L. Sutureless closed hemorrhoidectomy: a new technique. Ann Surg 2001;234(1):21-4.

[2] Shalaby R, Desoky A. Randomized clinical trial of stapled versus milligan-morgan haemorrhoidectomy. Br J Surg 2001;88(8):1049-53.

[3] Milligan ETC, Morgan CN, Jones LE, et al. Surgical anatomy of the anal canal and the operative treatment of hemorrhoids. Lancet 1937;230(5959):119-24.

[4] Mehigan BJ, Monson JR, Hartley JE. Stapling procedure for haemorrhoids versus milligan-morgan haemorrhoidectomy: randomised controlled trial. Lancet 2000;355(9206):782-5.

[5] Rowsell M, Bello M, Hemingway DM. Circumferential mucosectomy (stapled haemorrhoidectomy) versus conventional haemorrhoidectomy: randomised controlled trial. Lancet 2000;355(9206):779-81.

[6] Ganio E, Altomare DF, Gabrielli F, et al. Prospective randomized multicentre trial comparing stapled with open haemorrhoidectomy. Br J Surg 2001;88(5):66974.
[7] Correa-Rovelo JM, Tellez O, Obregon L, et al. Stapled rectal mucosectomy vs. closed hemorrhoidectomy: a randomized clinical trial. Dis Colon Rectum 2002;45(10):1367-74.

[8] Hetzer FH, Demartines N, Handschin AE, et al. Stapled vs excisional hemorrhoidectomy: long-term results of a prospective randomized trial. Arch Surg 2002;137(3):337-40.

[9] Singer MA, Cintron JR, Fleshman JW, et al. Early experience with stapled hemorrhoidectomy in the United States. Dis Colon Rectum 2002;45(3):360-7.

[10] Fazio VW. Early promise of stapling technique for haemorrhoidectomy. Lancet 2000;355(9206):768-9.

[11] Khalil KH, O'Bichere A, Sellu D. Randomized clinical trial of sutured versus stapled closed haemorrhoidectomy. Br J Surg 2000;87(10):1352-5.

[12] Tjandra JJ, Chan MKY. Systematic review on the procedure for prolapse and hemorrhoids stapled hemorrhoidopexy. Dis Colon Rectum 2007;50(6):87892.

[13] Bikhchandani J, Agarwal PN, Kant R, et al. Randomized controlled trial to compare the early and mid-term results of stapled versus open hemorrhoidectomy. Am J Surg 2005;189(1):56-60.

[14] Stolfi VM, Sileri P, Micossi C, et al. Treatment of hemorrhoids in day surgery: stapled hemorrhoidopexyvs milligan-morgan hemorrhoidectomy. J Gastrointest Surg 2008; 12(5):795-801.

[15] $\mathrm{Ng} \mathrm{KH,} \mathrm{Ho} \mathrm{KS,} \mathrm{Ooi} \mathrm{BS,} \mathrm{et} \mathrm{al.} \mathrm{Experience} \mathrm{of} 3711$ stapled haemorrhoidectomy operations. $\mathrm{Br} \quad \mathrm{J}$ Surg 2006;93(2):226-30.

[16] Jayaraman S, Colquhoun PH, Malthaner RA. Stapled versus conventional surgery for haemorrhoids. Cochrane Database Syst Rev 2006;4:CD005393. 